\title{
Evaluation of potential anti-toxoplasmosis efficiency of combined traditional herbs in a mouse model ${ }^{*}$
}

\author{
Xun-hui ZHUO ${ }^{1,2}$, Hong-chao $\mathrm{SUN}^{1}$, Bin $\mathrm{HUANG}^{1}$, Hai-jie $\mathrm{YU}^{3}$, Ying SHAN ${ }^{1}$, Ai-fang DU ${ }^{\dagger 1}$ \\ ${ }_{(}^{I}$ Institute of Preventive Veterinary Medicine \& Zhejiang Provincial Key Laboratory of Preventive Veterinary Medicine, \\ College of Animal Sciences, Zhejiang University, Hangzhou 310058, China) \\ ( ${ }^{2}$ Department of Immunity and Biochemistry, Institute of Parasitic Disease, Zhejiang Academy of Medical Sciences, Hangzhou 310013, China) \\ ( ${ }^{3}$ Jiaxing Vocational \& Technical College, Jiaxing 314000, China) \\ †E-mail: afdu@zju.edu.cn
}

Received July 12, 2016; Revision accepted Aug. 26, 2016; Crosschecked May 10, 2017

\begin{abstract}
Toxoplasma gondii is a worldwide spread protozoan and is able to infect almost all warm-blood animals. No effective drugs are available clinically on toxoplasmosis. Chinese traditional herbal medicines have provided remedies for many health problems. There exists a possibility that Chinese herbs may provide protection against $T$. gondii. This work aims to assess the protective efficacy of combined Chinese herbs against $T$. gondii. We screened five herbal medicines that have different pharmacological effects and combined them into a prescription according to the traditional Chinese medicine compatibility principle. The drug potential and protective efficacy were evaluated through a mouse model by determining the survival time, the parasite load in blood and tissues, the change of cell proportions in blood and histological detection. The results showed that the survival time of mice in the $500 \mathrm{mg}$ Chinese herbs group and sulfadiazine group was significantly longer than that of the PBS control group. Also the parasite load in blood and tissues of $500 \mathrm{mg}$ Chinese herbs and sulfadiazine groups was significantly lower than that of PBS group at 7 days post infection (dpi), which was in accordance with the result of histological detection. Monocyte and neutrophil of infected mice were remarkably increased while lymphocyte was dramatically decreased compared to that of blank group at $7 \mathrm{dpi}$. The results demonstrated that the $500 \mathrm{mg}$ dosage of our Chinese herbs could slow down the replication of $T$. gondii and prolong the survival time of mice and could be considered as possible candidate drug against toxoplasmosis.
\end{abstract}

Key words: Toxoplasma gondii; Chinese herbs; Real-time PCR; Survival; Protection http://dx.doi.org/10.1631/jzus.B1600316

CLC number: $5855.9+9$

\section{Introduction}

Toxoplasmosis caused by the intracellular protozoan Toxoplasma gondii is a ubiquitous worldwide parasitic zoonotic disease (Innes, 2010a). It is usually asymptomatic in immune-competent individuals but may occasionally lead to severe ocular and neurological disorders (Furtado et al., 2013). When it comes to immune-compromised and congenitally

\footnotetext{
\$Corresponding author

* Project supported by the Science and Technology Department of Zhejiang Province (No. 2012C12009-2), China

(b) ORCID: Ai-fang DU, http://orcid.org/0000-0002-3796-6621

(C) Zhejiang University and Springer-Verlag Berlin Heidelberg 2017
}

infected individuals, toxoplasmosis can result in lethal systemic disease and eventually death (Shen et al., 2016). Currently, the control of T. gondii mainly depends on chemotherapy, such as the combination of sulfadiazine and pyrimethamine, but these drugs have serious side effects (Petersen and Schmidt, 2003). Even though many antigens including rhoptry, surface, and dense granule excreted-secreted antigens were evaluated as potential vaccines (Kur et al., 2009), there is no licensed vaccine against $T$. gondii infection clinically making the situation even worse (Jongert et al., 2009; Innes, 2010b). Therefore, new efficient drugs and safe protective therapies are needed. 
Artemisinin isolated from a Chinese traditional medicine Artemisia annua is now included in standard treatment worldwide for Plasmodium falciparum malaria. Subsequent to that, interest in Chinese traditional medicine has risen to be considered for providing therapeutic reagents for many infectious diseases. The Radix clematidis extract is reported to be a potent inhibitor of matrix metalloproteinase-9 (MMP-9) and notably blocks the nuclear factor- $\mathrm{kB}$ $(\mathrm{NF}-\mathrm{kB})$ pathway in breast carcinoma cells (Noh et al., 2011). Na-Bangchang and Karbwang (2014) found that a Chinese traditional medicine Atractylodes possesses various pharmacological effects with anticancer, anti-inflammatory and antimicrobial activity, and is now a potential chemotherapeutic for cholangiocarcinoma found in Southeast Asia. Artemisia anomala has been widely and in long-term used for the treatment of inflammatory diseases in China. Recent findings suggested that it manifests its antiinflammatory effects through inhibiting the expression of inducible nitric oxide synthase (iNOS) (Tan et al., 2014). Glycyrrhizin, extracted from Liquorice, was reported to have antiviral activity through inhibiting replication of the pathogen (Cinatl et al., 2003).

Throughout history, Chinese traditional herbal medicines have provided many remedies for many health problems. The use of most herbal medicines dates back almost 2000 years in Shennong's Materia Medica. However, limited information is available on their pharmacological activity since the use of herbal medicine has been based mainly on empirical treatment. As a consequence, there exists a possibility that many herbal medicines may have unknown effects on different health problems. In this study, we screened five herbal medicines that have different pharmacological effects and combined them into a prescription according to the traditional Chinese medicine compatibility principle. We evaluated the protective efficacy provided by the different dosages of this prescription against the challenge of RH strain of $T$. gondii in a mouse model.

\section{Materials and methods}

\subsection{Animals}

Female ICR mice (6-8 weeks old) were kept in an animal experimentation laboratory under standard conditions according to the guidelines of the Regulation for the Administration of Affairs concerning Experimental Animals of the People's Republic of China. These experiments on mice were approved by Zhejiang University Experimental Animal Ethics Committee (No. ZJU201308-1-10-072).

\subsection{Parasites}

Tachyzoites of $T$. gondii RH strain were maintained in ICR mice by intraperitoneal (i.p.) serial passage at regular $72 \mathrm{~h}$ intervals. The parasites were washed three times by phosphate-buffered saline (PBS) and centrifuged at $1000 \mathrm{~g}$ for $5 \mathrm{~min}$ as previously described (Mack and McLeod, 1984).

\subsection{Drugs}

Five kinds of Chinese herbal medicines were purchased from Huqingyu Tang Pharmaceutical Co., Ltd., Hangzhou, China. According to the traditional Chinese medicine compatibility principle, they were combined as follows: R. clematidis (10 g), Fructus Ulmi Macrocarpae (8 g), Atractylodes (15 g), A. anomala $(10 \mathrm{~g})$, and Glycyrrhizae $(6 \mathrm{~g})$. On the basis of the traditional Chinese medicine decoction method, herbal drugs were boiled for $3 \mathrm{~h}$ in water $(1 \mathrm{~L})$ followed by concentrating through a rotary evaporator into $2 \mathrm{~g} / \mathrm{ml}$ of the whole drugs. Sulfadiazine as a positive control drug was purchased from Novartis (Beijing, China).

\subsection{Effect of drugs on $\boldsymbol{T}$. gondii infection in vivo}

A total of 140 female mice were randomly divided into seven groups (A to $G$ ). Mice in groups B-G were i.p. infected with $1 \times 10^{3}$ tachyzoites of $T$. gondii RH strain. Different medical administrations were carried out after infection with $T$. gondii $\mathrm{RH}$ strain as follows: Group A, blank control; Group B, PBS control; Group $\mathrm{C}$, mice were treated with $10 \mathrm{mg} / \mathrm{d}$ of sulfadiazine through oral gavage; mice in Groups $D-G$ were treated with Chinese herbs through oral gavage in single dosages of 300,400 , 500 , and $600 \mathrm{mg} / \mathrm{d}$, respectively, according to the Chinese Pharmacopoeia (National Pharmacopoeia Committee, 2010).

The animals were observed daily for mortality. A total of three mice in each group were euthanized at 3 and 7 days post infection (dpi), when whole blood was collected for a blood routine test; liver, spleen, 
and lung tissues were collected for quantitative realtime polymerase chain reaction (PCR) and histological section assay.

\subsection{Real-time PCR for detection of $T$. gondii DNA in tissues}

The presence of $T$. gondii DNA was investigated by real-time PCR based on the SAG1 gene as described previously (Yu et al., 2013). The genomic DNA of blood, liver, spleen, and lung tissues was extracted using a Universal Genomic DNA Extraction Kit (TaKaRa, China) according to the manufacturer's instructions. The forward and reverse primer sequences used in this study were 5'-CTGATGTCG TTCTTGCGATGTGGC-3' and 5'-GTGAAGTGGT TCTCCGTCGGTGT-3', respectively, designed by the Primer Express software (PE Applied Biosystem), which could amplify a 128-bp fragment under predetermined conditions. SYBR ${ }^{\circledR}$ Green was then used to detect fluorescence using the $\mathrm{QQ}^{\mathrm{TM}}$ Real-Time PCR System (Bio-Rad). Sterile water and genomic DNA of $T$. gondii tachyzoites were included as negative and positive controls in each run. In addition, a plasmid pMD-SAG1 was constructed based on pMD18-T vector using the same primers. To establish standard curves, plasmid pMD-SAG1 was tenfold serially diluted ranging from $2 \times 10^{4}$ to $2 \times 10^{9}$ copies per milliliter tested in each independent experiment for $T$. gondii quantification. Each sample had three parallel wells and was detected three times.

\subsection{Blood routine test}

At least $30 \mu 1$ of anticoagulated blood samples collected from mice of different groups at 3 and $7 \mathrm{dpi}$ were applied to an IDEXX ProCyte Dx ${ }^{\circledR}$ hematology analyzer. Each blood sample was read three times. The data were analyzed using the software SPSS 16.0 for Windows (SPSS Inc., Chicago, IL, USA) and statistical difference was accepted at the level of $P<0.05$.

\subsection{Histological section assay of tissues}

Liver, spleen, and lung tissue specimens from different groups were first fixed in $10 \%$ (v/v) buffered formalin and then processed to paraffin for embedding. Tissue sections were obtained at approximately $5-\mu \mathrm{m}$ thickness and stained with haematoxylin and eosin $(\mathrm{H} \& \mathrm{E})$ stains as described previously (Fischer et al., 2008). Sections were examined under light microscopy.

\section{Results}

3.1 Protection of mice against challenge with $T$. gondii RH strain

In order to determine whether these combined Chinese herbs could provide effective protection against $T$. gondii RH infection, mortality was recorded daily following the $T$. gondii challenge until all mice were dead and survival curves of all groups were generated as shown in Fig. 1. The survival time of mice in the sulfadiazine group $((13.5 \pm 2.0) \mathrm{d})$ and $500 \mathrm{mg}$ Chinese herb group $((9.8 \pm 0.69) \mathrm{d})$ were significantly longer than that in the PBS control group $(6.9 \pm 0.18 \mathrm{~d})(P<0.05)$. The average survival time of mice in the 300,400 , and $600 \mathrm{mg}$ Chinese herb groups was all under $8 \mathrm{~d}$ which was slightly longer than that of PBS group, but the difference was not statistically significant $(P>0.05)$.

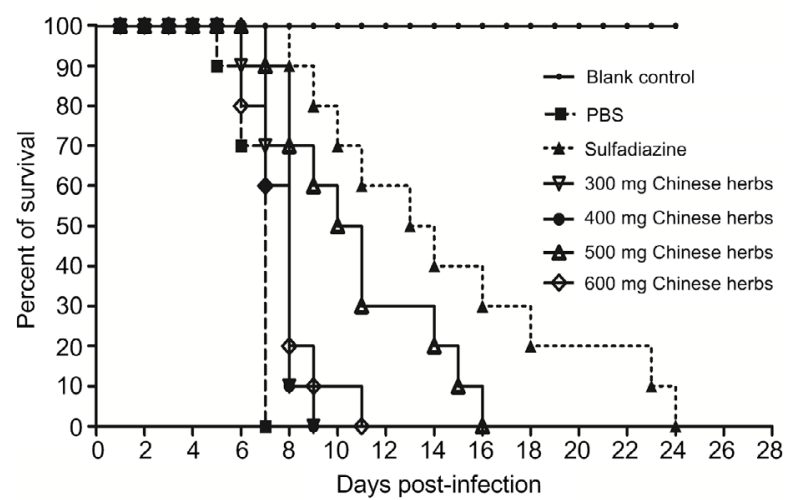

Fig. 1 Evaluation of survival curves against the lethal challenge of Toxoplasma gondii

Survival rate of mice treated with sulfadiazine and different dosages of Chinese herbs after challenge with $1 \times 10^{3}$ tachyzoites of T. gondii RH strain. Mice treated with PBS were included as negative control and mice infected with no T. gondii were included as blank control. Survival rate was monitored daily until all infected-mice died ( $n=10$ mice per group)

\subsection{Real-time PCR for detection of $T$. gondii DNA}

Blood and tissue samples were collected from different experimental groups at 3 and 7 dpi with $T$. gondii, and then DNA was extracted as the template for SAG1-based real-time PCR to evaluate the parasite loads and DNA copy number in $T$. gondiiinfected mice (Fig. 2). Every blood and tissue DNA sample was tested in triplicate and no amplification products were observed in wells from the blank control group. Results from the blood are shown in Fig. 2a. Parasite loads in all groups at 7 dpi were 

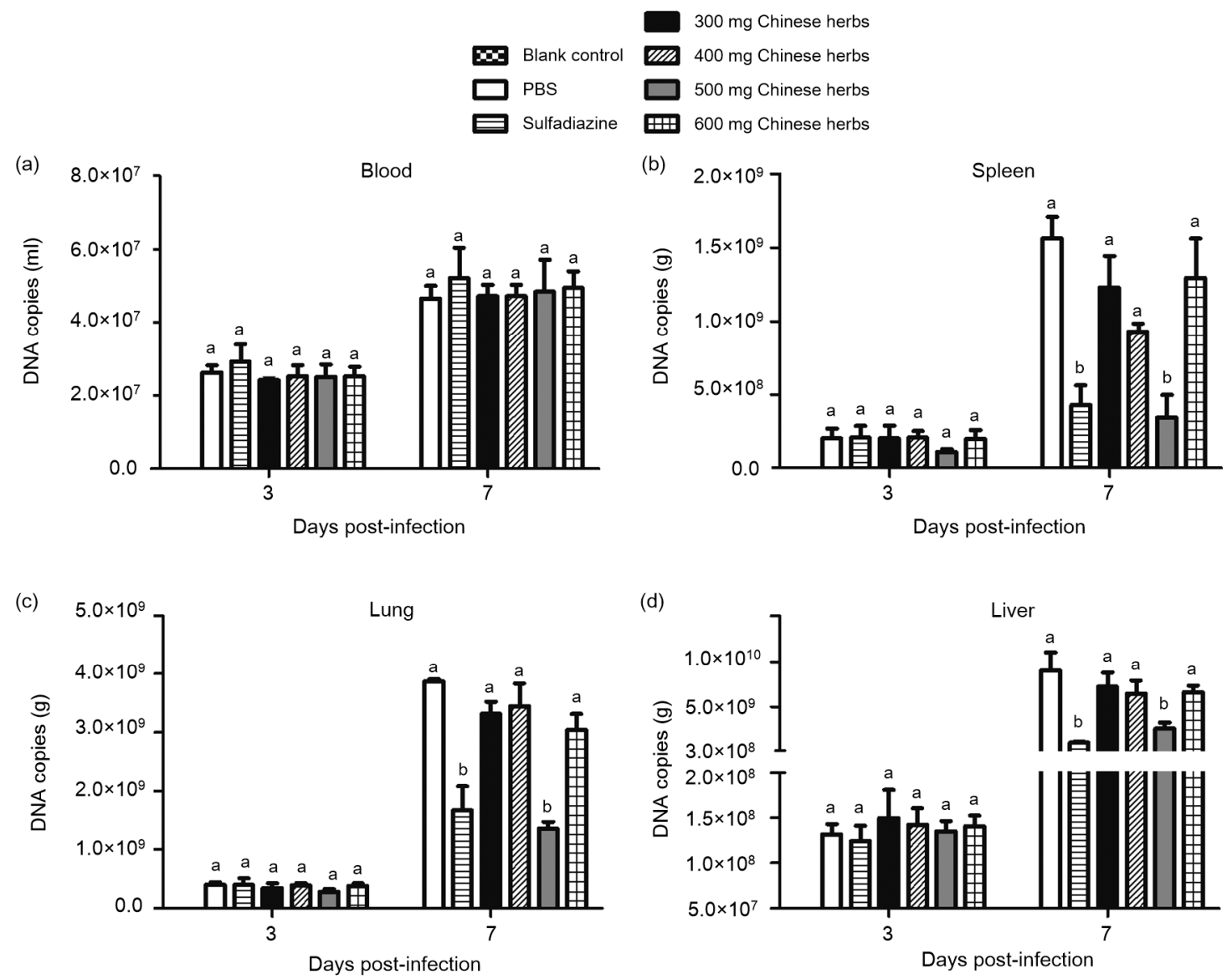

Fig. 2 Determination of the parasite load in blood, spleen, lung, and liver at 3 and 7 dpi

Blood (a), spleen (b), lung (c), and liver (d) tachyzoite burdens at 3 and $7 \mathrm{~d}$ after challenge. The DNA copies of T. gondii (per milliliter blood or per gram tissue) in blood and tissues of mice after challenge with $1 \times 10^{3}$ tachyzoites of T. gondii RH strain per mouse. The counting of DNA copies of $T$. gondii has been done in triplicate for each tissue and for three mice from each group. Values are expressed as mean \pm SD. Columns with different letters present statistical difference $(P<0.05)$

almost double that at 3 dpi, but no significant difference was observed among these groups. Results of spleen, lung, and liver tissues presented a similar pattern (Figs. 2b-2d) in that parasite loads were all largely increased from 3 to $7 \mathrm{dpi}$, and mice of the PBS control group had statistically significantly higher parasite load compared with sulfadiazine and $500 \mathrm{mg}$ Chinese herb groups $(P<0.05)$. However, the parasite loads of mice in 300,400 , and $600 \mathrm{mg}$ Chinese herb groups were all fewer than those in the PBS control group but not at a statistically significant level.

\subsection{Blood routine test}

Blood samples were collected from different groups at 3 and 7 dpi directly into a $1-\mathrm{ml}$ tube containing $0.3 \mathrm{mg}$ dipotassium ethylenediamine tetraacetic acid $\left(\mathrm{K}_{2}\right.$ EDTA) and analyzed by an IDEXX ProCyte $\mathrm{Dx}^{\circledR}$ hematology analyzer. No significant increases were observed in eosinophil among the different $T$. gongdii-infected groups (Fig. 3a). The proportion of monocyte of infected mice was remarkably increased compared to that of the blank group at $7 \mathrm{dpi}$ (Fig. 3b; $P<0.05)$. However, lymphocytes of the infected groups were dramatically decreased compared with the blank control group (Fig. 3c) and those of the sulfadiazine and $500 \mathrm{mg}$ Chinese herb groups were significantly low compared to the other four infected groups $(P<0.05)$. As shown in Fig. 3d, neutrophil in the infected groups was increased more than double compared to the blank control group at $7 \mathrm{dpi}(P<0.05)$, and the sulfadiazine and $500 \mathrm{mg}$ Chinese herb groups also increased significantly higher among these groups. 

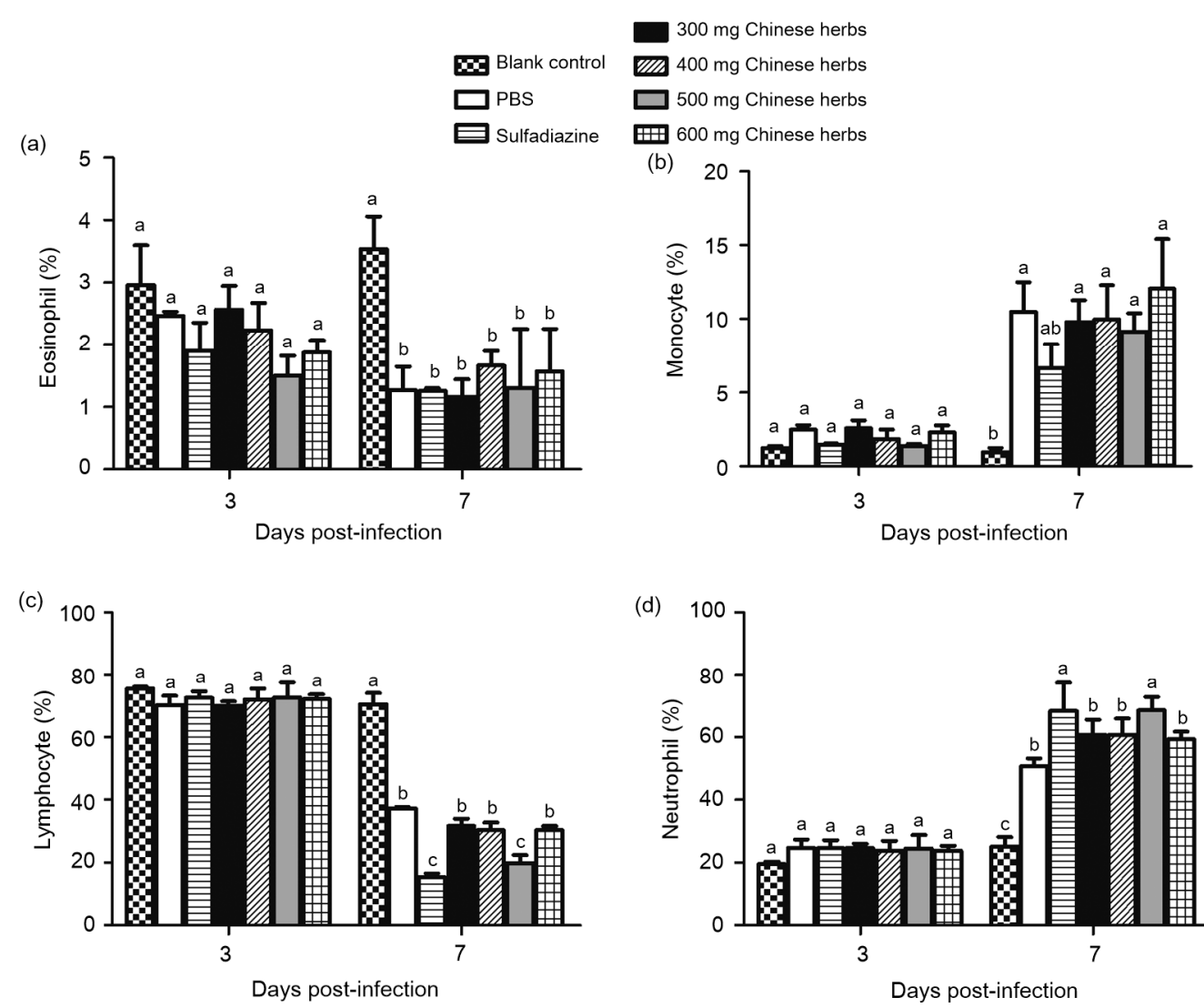

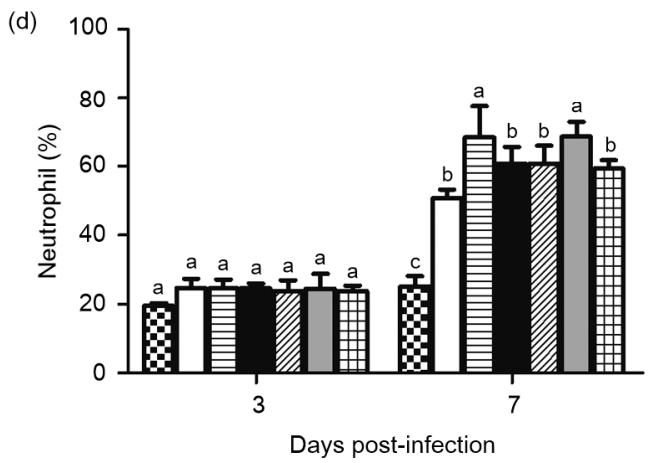

Fig. 3 Assessment of blood routine test at 3 and $7 \mathrm{~d}$ after the lethal challenge of Toxoplasma gondii

The results showed the percentage of cells in blood at 3 and $7 \mathrm{~d}$ after challenge with $1 \times 10^{3}$ tachyzoites of $T$. gondii RH strain per mouse. Eosinophil (a), monocyte (b), lymphocyte (c), and neutrophil (d) cell percentages were analyzed by IDEXX ProCyte Dx ${ }^{\circledR}$ hematology analyzer at 3 and $7 \mathrm{dpi}$. Blood samples were collected from three mice at each group at 3 and 7 dpi, respectively. Values are expressed as mean $\pm \mathrm{SD}$. Columns with different letters present statistical difference $(P<0.05)$

\subsection{Pathologic changes detected by histological section assay of tissues}

Pathological studies were performed through histological sections of liver, lung, and spleen tissues which were collected at $7 \mathrm{dpi}$ from all groups. The livers of sulfadiazine and $500 \mathrm{mg}$ Chinese herbs-treated mice displayed few changes compared to normal mice (Figs. $4 \mathrm{c}$ and $4 \mathrm{f}$ ), but the livers of the PBS group mice showed a clear cellular separation, which revealed its morphologically incomplete and hepatocellular dysfunction (Fig. 4b), and the livers of 300, 400, and $600 \mathrm{mg}$ Chinese herbs-treated mice showed slightly more cellular separation (Figs. $4 \mathrm{~d}-$ $4 \mathrm{~g})$. The lungs of all $T$. gondii-infected mice represented interstitial pneumonia at different degrees with much thicker alveolar walls compared to that of the blank control group (Figs. 4i-4n), and more severe cellular damage was observed in 300 and $600 \mathrm{mg}$
Chinese herbs-treated mice and the PBS control group. The spleen of the PBS group was extensively necrotic with few lymphoid cells and plenty of scattered cells observed. Lymphoid follicles were also absent (Fig. 4p). The spleens of other groups also had evidence of necrosis and degeneration with small scattered nodules of dead lymphoid cells (Figs. 4q$4 \mathrm{u}$ ), but they were not as deteriorated as that of the PBS group shown in Fig. $4 p$.

\section{Discussion}

$T$. gondii can infect almost all warm-blooded animals, but no available drugs can eliminate this pathogen from its host without any clinical side effects. The discovery of artemisinin, isolated from $A$. апnиa, which can provide effective treatment worldwide against $P$. falciparum malaria, raises the 


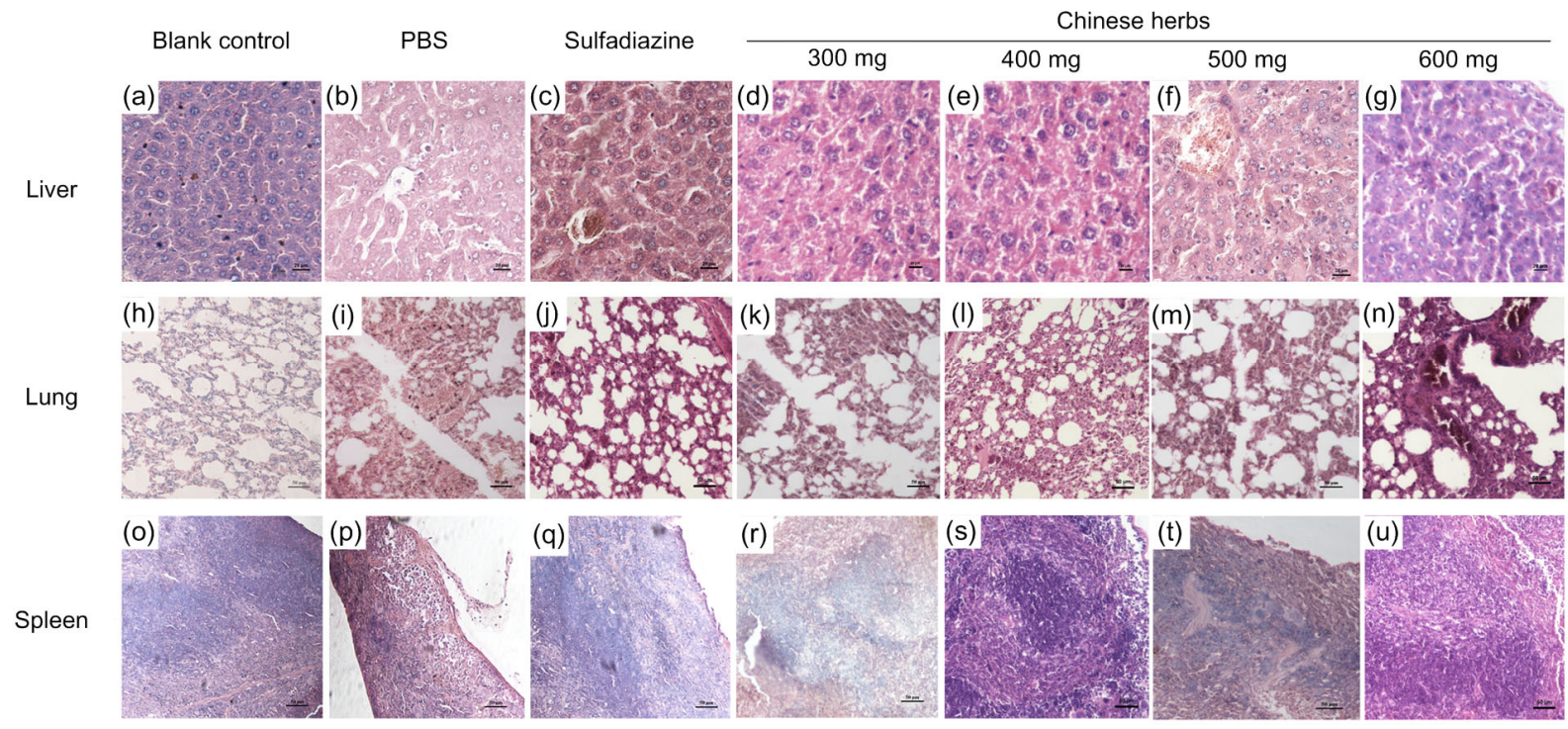

Fig. 4 Pathological examinations of spleen, lung, and liver tissues after the lethal challenge of Toxoplasma gondii Pathological examinations were based on $\mathrm{H} \&$ E-stained $5 \mu \mathrm{m}$-thick longitudinal sections of liver, lung, and spleen tissues in each group at 7 dpi. Liver $(a-g)$, lung $(h-n)$, and spleen $(\mathrm{o}-\mathrm{u})$ were collected from seven groups. Scale bars represent $20 \mu \mathrm{m}(\mathrm{a}-\mathrm{g})$ and $50 \mu \mathrm{m}(\mathrm{h}-\mathrm{u})$

question as to whether Chinese traditional medicines could afford protection against $T$. gondii. Therefore, five herbal medicines that have different pharmacological effects were screened and combined into a prescription according to the traditional Chinese medicine compatibility principle and then the drug potential and protective efficacy were evaluated through a mouse model.

Molecular methods, particularly real-time PCR, have been treated as sensitive and reliable tools for determining the parasite loads of $T$. gondii (Bell and Ranford-Cartwright, 2002; Li et al., 2012). Hence, we applied an SAG1-based real-time PCR method to determine the parasite loads in blood and tissues. We found $T$. gondii DNA could be detected in blood and tissues from all infected groups at 3 dpi with a relatively high level and was almost all doubled from 3 to 7 dpi while no significant difference was observed among these groups.

The level of the parasite load of the liver of sulfadiazine and $500 \mathrm{mg}$ Chinese herbs-treated groups was lower than that of the PBS control group $(P<$ 0.05 ). We also found the livers of sulfadiazine and $500 \mathrm{mg}$ Chinese herbs-treated mice displayed few changes while a clear cellular separation could be observed in the liver of PBS group mice that presented a morphologically incomplete and hepatocellular dysfunction. The lungs of sulfadiazine and Chinese herbs-treated mice possessed a significantly lower parasite load than that of the PBS control group $(P<0.05)$ and the histological result verified this from the morphological perspective. The lungs of all $T$. gondii-infected mice displayed interstitial pneumonia which had much thicker alveolar walls compared to those of the blank control group. However, the situations of the PBS group, the 300 and $600 \mathrm{mg}$ Chinese herbs-treated groups were the worst such that no complete pulmonary alveoli structure could be observed. This revealed the fact that the lungs barely functioned and resulted in rapid death at $7 \mathrm{dpi}$ as shown in the survival curve. As for the spleen, the parasite in sulfadiazine and $500 \mathrm{mg}$ Chinese herbstreated groups was at a significantly lower level than that in the PBS group at $7 \mathrm{dpi}(P<0.05)$. The spleens of all infected mice showed necrosis and degeneration. Lymphoid follicles of the PBS group were barely observed, and those of sulfadiazine and $500 \mathrm{mg}$ Chinese herbs-treated groups also had evidence of necrosis and degeneration with small scattered nodules of dead lymphoid cells. These results were in accordance with the survival curve that the mice of sulfadiazine and $500 \mathrm{mg}$ Chinese herb groups lived much longer than the controls. Mice treated with $500 \mathrm{mg}$ Chinese herbs $((9.8 \pm 0.69)$ d) showed a 
significantly longer survival time $(P<0.05)$ than the PBS-treated mice. In addition, the average survival time of $500 \mathrm{mg}$ Chinese herbs-treated mice presented a similar level as many studies on DNA vaccines; the average survival time of rROP18-immunized ICR mice is $11.5 \mathrm{~d}$ (Qu et al., 2013) and Zheng et al. (2013) found that after being immunized with rROP5+ rSAG1, mice had prolonged survival time of $12.1 \mathrm{~d}$. We assume that $T$. gondii was able to move to most tissues of mice through blood based on the fact that DNA copies of $T$. gondii had been detected in blood, liver, spleen, and lung. Actually, Dadimoghaddam et al. (2014) found $T$. gondii moved to various tissues within $24 \mathrm{~h}$ after i.p. injection and the largest number of parasites was observed in the heart, kidney, and liver. The movement trend of $T$. gondii and parasite load in tissues have been used mainly to evaluate the vaccine effect, anti-parasite and drug disease severity (Bell and Ranford-Cartwright, 2002; Romand et al., 2004). The results gathered here suggested that these combined Chinese herbs could afford efficient protection against acute $T$. gondii infection.

Machado et al. (2014) demonstrated that the increased monocytes and lymphocytes could be treated as a relevant hematological biomarker of acute retinochoroidal lesions caused by $T$. gondii. Thus we used an IDEXX ProCyte Dx ${ }^{\circledR}$ hematology analyzer to determine the changes of cell proportions in blood at 3 and $7 \mathrm{dpi}$. We found that there was no significant difference among the $T$. gondii infected groups on eosinophil at 3 or $7 \mathrm{dpi}$. However, monocytes and neutrophils of infected mice were remarkably increased while lymphocytes were dramatically decreased compared to those of the blank control group at $7 \mathrm{dpi}$. On the other hand, the significantly lower lymphocyte and slighter lower monocyte of sulfadiazine and $500 \mathrm{mg}$ Chinese herbs-treated mice than those of other Chinese herbs-treated mice suggests that effective drugs may decrease the cell proportions to hinder the cellular transmission of $T$. gondii. There are no differences between normal mice and infected mice at 3 dpi. We found $T$. gondii was capable of escaping the immune system in blood when combining the results of parasite load in blood at $3 \mathrm{dpi}$. In accordance with the results of Machado et al. (2014), the monocytes were increased drastically at 7 dpi. The recruitment of monocytes is essential in restricting the replication of the $T$. gondii murine model (Mordue and Sibley, 2003; Robben et al., 2005). On the other hand, monocytes as well as neutrophils and eosinophils are strong candidates for transport of $T$. gondii in blood in a way known as a "Trojan Horse" (Lachenmaier et al., 2011), so the activity of monocyte must be carefully controlled. However, the trend of lymphocytes was opposite to that of Machado et al. (2014). The percentage of lymphocytes was decreased in infected mice mainly because ICR mice were sensitive to $T$. gondii and failed to eliminate the parasite, which was in accordance with the result that all infected mice eventually died.

In summary, mice treated with Chinese herbal medicines had been showed to elicit partial protection against acute $T$. gondii infection. Moreover, our study indicated that $500 \mathrm{mg}$ Chinese herbs could afford more efficient protection than the other three dosages. The results also suggested that our $500 \mathrm{mg}$ Chinese herbs could slow down the replication of $T$. gondii and prolong the survival time of mice. These results demonstrated this combination of Chinese herbs could be considered as possible candidate drugs against toxoplasmosis and also that the therapies of traditional Chinese herbal medicine can be developed for anti-Toxoplasma in the future.

\section{Compliance with ethics guidelines}

Xun-hui ZHUO, Hong-chao SUN, Bin HUANG, Hai-jie YU, Ying SHAN, and Ai-fang DU declare that they have no conflict of interest.

All institutional and national guidelines for the care and use of laboratory animals were followed.

\section{References}

Bell, A., Ranford-Cartwright, L., 2002. Real-time quantitative PCR in parasitology. Trends Parasitol., 18(8):338-342. http://dx.doi.org/10.1016/S1471-4922(02)02331-0

Cinatl, J., Morgenstern, B., Bauer, G., et al., 2003. Glycyrrhizin, an active component of liquorice roots, and replication of SARS-associated coronavirus. Lancet, 361(9374):20452046. http://dx.doi.org/10.1016/S0140-6736(03)13615-X

Dadimoghaddam, Y., Daryani, A., Sharif, M., et al., 2014. Tissue tropism and parasite burden of Toxoplasma gondii RH strain in experimentally infected mice. Asian Pac. J. Trop. Med., 7(7):521-524. http://dx.doi.org/10.1016/S1995-7645(14)60087-0

Fischer, A.H., Jacobson, K.A., Rose, J., et al., 2008. Hematoxylin and eosin staining of tissue and cell sections. Cold Spring Harb. Protoc, 2008(5):pdb.prot4986. 
http://dx.doi.org/10.1101/pdb.prot4986

Furtado, J.M., Winthrop, K.L., Butler, N.J., et al., 2013. Ocular toxoplasmosis I: parasitology, epidemiology and public health. Clin. Exp. Ophthalmol., 41(1):82-94. http://dx.doi.org/10.1111/j.1442-9071.2012.02821.x

Innes, E.A., 2010a. A brief history and overview of Toxoplasma gondii. Zoonoses Public Hlth., 57(1):1-7. http://dx.doi.org/10.1111/j.1863-2378.2009.01276.x

Innes, E.A., 2010b. Vaccination against Toxoplasma gondii: an increasing priority for collaborative research? Expert Rev. Vacc., 9(10):1117-1119. http://dx.doi.org/10.1586/erv.10.113

Jongert, E., Roberts, C.W., Gargano, N., et al., 2009. Vaccines against Toxoplasma gondii: challenges and opportunities. Mem. Inst. Oswaldo Cruz., 104(2):252-266. http://dx.doi.org/10.1590/S0074-02762009000200019

Kur, J., Holec-Gasior, L., Hiszczynska-Sawicka, E., 2009. Current status of toxoplasmosis vaccine development. Expert Rev. Vaccines, 8(6):791-808. http://dx.doi.org/10.1586/erv.09.27

Lachenmaier, S.M., Deli, M.A., Meissner, M., et al., 2011. Intracellular transport of Toxoplasma gondii through the blood-brain barrier. J. Neuroimmunol., 232(1):119-130. http://dx.doi.org/10.1016/j.jneuroim.2010.10.029

Li, C., Ying, Q., Su, X., et al., 2012. Development and application of reverse transcription loop-mediated isothermal amplification for detecting live Shewanella putrefaciens in preserved fish sample. J. Food Sci., 77(4): M226-M230. http://dx.doi.org/10.1111/j.1750-3841.2012.02636.x

Machado, A.S., Carneiro, A.C., Bela, S.R., et al., 2014. Biomarker analysis revealed distinct profiles of innate and adaptive immunity in infants with ocular lesions of congenital toxoplasmosis. Mediat. Inflamm., 2014:910621. http://dx.doi.org/10.1155/2014/910621

Mack, D.G., McLeod, R., 1984. New micromethod to study the effect of antimicrobial agents on Toxoplasma gondii: comparison of sulfadoxine and sulfadiazine individually and in combination with pyrimethamine and study of clindamycin, metronidazole, and cyclosporin A. Antimicrob. Agents Chemother., 26(1):26-30. http://dx.doi.org/10.1128/AAC.26.1.26

Mordue, D.G., Sibley, L.D., 2003. A novel population of Gr- $1^{+}$-activated macrophages induced during acute toxoplasmosis. J. Leukoc. Biol., 74(6):1015-1025. http://dx.doi.org/10.1189/jlb.0403164

Na-Bangchang, K., Karbwang, J., 2014. Traditional herbal medicine for the control of tropical diseases. Trop. Med. Health, 42(2 Suppl.):S3-S13.

http://dx.doi.org/10.2149/tmh.2014-S01

National Pharmacopoeia Committee, 2010. Pharmacopoeia of People Republic of China. Chemical Industry Press, Beijing, China (in Chinese).

Noh, E.M., Lee, Y.R., Hur, H., et al., 2011. Radix clematidis extract inhibits TPA-induced MMP-9 expression by suppressing NF- $\kappa \mathrm{B}$ activation in MCF-7 human breast cancer cells. Mol. Med. Rep., 4:879-883.

http://dx.doi.org/10.3892/mmr.2011.532

Petersen, E., Schmidt, D.R., 2003. Sulfadiazine and pyrimethamine in the postnatal treatment of congenital toxoplasmosis: what are the options? Expert Rev. Anti-infect. Ther., 1(1):175-182. http://dx.doi.org/10.1586/14787210.1.1.175

Qu, D., Han, J., Du, A., 2013. Enhancement of protective immune response to recombinant Toxoplasma gondii ROP18 antigen by ginsenoside Re. Exp. Parasitol., 135(2):234-239. http://dx.doi.org/10.1016/j.exppara.2013.07.013

Robben, P.M., LaRegina, M., Kuziel, W.A., et al., 2005. Recruitment of Gr- $1^{+}$monocytes is essential for control of acute toxoplasmosis. J. Exp. Med., 201(11):1761-1769. http://dx.doi.org/10.1084/jem.20050054

Romand, S., Chosson, M., Franck, J., et al., 2004. Usefulness of quantitative polymerase chain reaction in amniotic fluid as early prognostic marker of fetal infection with Toxoplasma gondii. Am. J. Obstet. Gynecol., 190(3): 797-802. http://dx.doi.org/10.1016/j.ajog.2003.09.039

Shen, G., Wang, X., Sun, H., et al., 2016. Seroprevalence of Toxoplasma gondii infection among HIV/AIDS patients in eastern China. Korean J. Parasitol., 54(1):93-96. http://dx.doi.org/10.3347/kjp.2016.54.1.93

Tan, X., Wang, Y.L., Yang, X.L., et al., 2014. Ethyl acetate extract of Artemisia anomala S. Moore displays potent anti-inflammatory effect. Evid. Based Complement. Alternat. Med., 2014:681352. http://dx.doi.org/10.1155/2014/681352

Yu, H., Huang, B., Zhuo, X., et al., 2013. Evaluation of a real-time PCR assay based on the single-copy SAG1 gene for the detection of Toxoplasma gondii. Vet. Parasitol., 197(3):670-673.

http://dx.doi.org/10.1016/j.vetpar.2013.06.013

Zheng, B., Lu, S., Tong, Q., et al., 2013. The virulence-related rhoptry protein 5 (ROP5) of Toxoplasma Gondii is a novel vaccine candidate against toxoplasmosis in mice. Vaccine, 31(41):4578-4584. http://dx.doi.org/10.1016/j.vaccine.2013.07.058

\section{中文概要}

题 目: 小鼠模型中研究复方中草药抗弓形虫感染的作用

目 的: 评估复方中草药对小鼠抗弓形虫的保护力, 以期 找到新型防治弓形虫病的药物。

创新点: 首次在小鼠模型中研究威灵仙、芜荑、白术、刘 寄奴和甘草组成的复方中草药的抗弓形虫功效, 并发现 $500 \mathrm{mg}$ 的药物能提供较好的保护力。

方 法: 将 ICR 雌性小鼠随机分为 7 组: 空白组不攻虫不 给药; PBS 组攻虫; 药物对照组攻虫并口服磺胺 嘧啶 $10 \mathrm{mg} / \mathrm{d}$; 实验组攻虫并分别灌胃 300、400、 
500 和 $600 \mathrm{mg} / \mathrm{d}$ 中药煎剂; 攻虫组每只小鼠腹腔 注射弓形虫 RH 株 1000 个。每日观察各组小鼠死 亡情况，在感染后 3 和 $7 \mathrm{~d}$ 采集抗凝血检测血常 规，并采集血液、肝、脾和肺组织，提取基因组 DNA, 通过绝对苂光定量 PCR 检测各组织样品 中的虫荷量, 采集感染后 $7 \mathrm{~d}$ 的肝、肺和脾组织, 制作组织切片, 通过 H \& E 染色观察组织病变情 况。

结 论: 试验结果表明, $500 \mathrm{mg}$ 中药组及磺胺嘧啶药物对 照组的小鼠显著地延长了存活时间（图 1)，且
这两组小鼠组织及血液中的虫荷数显著低于其 他组（图 2)，这与小鼠的肝、肺和脾组织病理 染色结果一致 (图 4)。另外, 与 300、400 和 $600 \mathrm{mg}$ 中药处理组相比, $500 \mathrm{mg}$ 处理组小鼠的 单核细胞和淋巴细胞比例均较低（图 3), 这在 一定程度上阻碍了弓形虫在血细胞中的传播。综 上所述, $500 \mathrm{mg}$ 中草药处理组能降低弓形虫的胞 内增殖速率, 延长小鼠的存活时间, 证明该浓度 的复方中药具有一定的抗弓形虫效果。

关键词: 弓形虫; 中草药; 苂光定量 PCR; 存活率 